\title{
Review Article \\ Chemical Cues for Malaria Vectors Oviposition Site Selection: Challenges and Opportunities
}

\author{
Yousif E. Himeidan, ${ }^{1}$ Emmanuel A. Temu, ${ }^{2}$ El Amin El Rayah, ${ }^{3}$ \\ Stephen Munga, ${ }^{4}$ and Eliningaya J. Kweka ${ }^{5,6}$ \\ ${ }^{1}$ Entomology Unit, Faculty of Agriculture and Natural Resources, University of Kassala, P.O. Box 266, Kassala, New Halfa, Sudan \\ ${ }^{2}$ Tropical Epidemiology Group, London School of Hygiene and Tropical Medicine, Keppel St, London WC1E 7HT, UK \\ ${ }^{3}$ Department of Zoology, University of Khartoum, P.O. Box 321, 1115 Khartoum, Sudan \\ ${ }^{4}$ Centre for Global Health Research, Kenya Medical Research Institute, P.O. Box 1578-40100, Kisumu, Kenya \\ ${ }^{5}$ Tropical Pesticides Research Institute, Division of Livestock and Human Diseases Vector Control, P.O. Box 3024, Arusha, Tanzania \\ ${ }^{6}$ Department of Medical Parasitology and Entomology, School of Medicine, Catholic University of Health and Allied Sciences, \\ P.O. Box 1464, Mwanza, Tanzania
}

Correspondence should be addressed to Eliningaya J. Kweka; pat.kweka@gmail.com

Received 25 August 2013; Accepted 19 October 2013

Academic Editor: Bruno Arcà

Copyright (C) 2013 Yousif E. Himeidan et al. This is an open access article distributed under the Creative Commons Attribution License, which permits unrestricted use, distribution, and reproduction in any medium, provided the original work is properly cited.

The attractiveness of oviposition site for malaria vector mosquitoes is dependent upon a number of physical and chemical factors. Many aspects of mosquito behavior, including host location and oviposition, are mediated by volatile semiochemicals. It is anticipated that selection of oviposition site by semio-chemicals in the form of attractants or stimulants can be used in oviposition traps to monitor or possibly in combination with insecticides to control gravid mosquito populations for mass trapping. So far, volatile compounds identified as oviposition attractants for mosquitoes include phenol, 4-methyl phenol, 4-ethyl phenol, indole, skatole, and $\mathrm{p}$-cresol from hay infusions; 3 -carene, $\alpha$-terpinene, $\alpha$-copaene, $\alpha$-cedrene, and $\mathrm{d}$-cadinene released by copepods; alcohol and terpenoids including p-cresol from plants; ethyl acetate and hydrocarbon substances, probably released by filamentous algae; 3-methyl-1-butanol identified from bacteria. Research priorities should be directed at identifying more oviposition attractants to determine the properties of these semio-chemicals for possible use in designing control tools. This would aim at luring females to lethal traps or stimulants to increase their exposure to insecticide-impregnated substrates.

\section{Background}

Malaria is one of the most significant and debilitating insecttransmitted human diseases and has infected humans for over thousand years and may have been a human pathogen for the entire history of mankind [1]. Today, malaria causes about 225 million cases of fever and approximately 600,000 deaths annually more specifically in children under age of 5 years [2]. This represents at least one death (child) every 39 seconds and 85-90\% of the deaths occur in sub-Saharan Africa [2].

Mosquitoes spend the first part of their lifecycle in aquatic habitats [3]. The choice of an appropriate oviposition sites has significant impact on the fitness of progeny, distribution of larvae, population dynamics, and the overall maternal reproductive fitness and success $[4,5]$. Oviposition process requires complex integration of physical and chemical cues by gravid mosquitoes. Long-range cues, probably involving vision, allow mosquitoes to identify different habitats and oviposition site characteristics. As mosquitoes approach an oviposition site other cues such as phenol, 4-methyl phenol, 4-ethyl phenol, indole, skatole, and p-cresol from hay infusions; 3 -carene, $\alpha$-terpinene, $\alpha$-copaene, $\alpha$-cedrene, and d-cadinene become important. Once oviposition site is identified, short-range cues become increasingly important. Short-range cues include temperature and chemical signals received by contact chemoreceptors [6]. 
Electrophysiological studies have demonstrated that as the blood meal is digested in Aedes aegypti, neurons sensitive to host-produced cues, such as lactic acid, become less sensitive, while neurons sensitive to oviposition site attractants, such as methyl butyrate, become more sensitive [7]. Understanding oviposition sites is therefore important to behavioral and vector ecologists because of its potential use in developing successful vector control strategies for insectborne infectious diseases [8]. A comprehensive knowledge of variations in oviposition behaviors and identification of their determinants that can be used as a repellant or attractant is a key step in this process.

\section{Mosquito Oviposition Site Selection}

2.1. Role of Habitat Characteristics. Oviposition site selection is the net result of the interaction of a complex array of both chemical and physical factors. The potential breeding sites of anopheline mosquito vectors differ in a range of characteristics, both biotic and abiotic $[9,10]$. Anopheline mosquitoes, particularly An. gambiae s.l., actively select habitats for enhancing survivorship and development of immature stages [11]. The source of these physical and chemical signals associated with these breeding sites act as important mediating factors.

The characteristics of potential breeding sites either singly or synergistically influence oviposition of gravid mosquitoes [12]. This occurs through several sensor factors including olfactory [13], tactile, temperature, chemical, and visual cues $[6,14]$. Chemical cues may be sensed before physical contact with the site, or they may be sensed upon contact [15] and may emanate from a variety of sources, including microorganisms; mosquito eggs, larvae, or pupae; decomposing organic materials; microbes of larval breeding water and predators or competitors, whether vertebrate or invertebrate $[5,6,16-23]$. Physical characteristics of water collections and their surroundings are assessed by gravid females for longrange identification of potential breeding sites, including color, optical density, reflectance, and temperature [24-26]. Certain physical factors influencing oviposition of Anopheles gambiae Giles are color/contrast of the substrate, water type, vegetation, presence of microorganisms, substrate moisture, and texture $[16,27,28]$.

The overall complex set of signals that are present in such breeding habitat and are used by An. gambiae to locate preferred oviposition site act in two contradictory ways. Whereas such habitats exert a "pulling" effect, unsuitable pools may exert an active "pushing" effect, and it is the integrated "push/pull" effects of these different signals that may effectively guide an insect to a habitat suitable for its species [3]. Previous studies designed to clarify the types of signals that mediate the attraction of An. gambiae to specific pools demonstrated mediation of several signals [21, 29]. Volatiles associated with the microbial population in preferred anopheline pools were found to be important initial interspecific attractants [21]. In general, two intraspecific signals were shown to regulate oviposition: a volatile pheromone and a contact deterrent associated with the larval stages of the mosquito [29]. This pair of signals may play an important role in fine-tuning the balance between the exploitation of a suitable breeding site and the avoidance of intra-specific competition and other effects of overcrowding [3, 29-33].

Attractant and repellent compounds for mosquitoes oviposition, including anopheline, have been identified from several sources such as hay infusion $[18,34]$, water-associated bacteria $[21,35,36]$, mosquito oviposition and larvae holding water, pheromones $[6,21,29,37]$, and exudates from aquatic competitors or predators $[13,38]$. The different sources of stimuli result in patterns of distribution of immature-stage mosquitoes that reflect differences in the suitability of sites for the development of different species $[29,39]$. Understanding this point is not only important for its potential in developing a new strategy, but also important in terms of targeting larval control. Here below are the main sources and substances mediating habitat selection that acts as repellent or attractants to gravid mosquitoes.

2.2. Immature Stages Conspecific. Gravid mosquitoes may be attracted to habitats with conspecific larvae, because presence of conspecific larvae may indicate suitable habitats for the species $[21,40,41]$. Conspecific attraction has been described as a means for females to exploit information collected by other females. Rather than gathering information on a multitude of environmental factors potentially affecting offspring growth, a process constrained by energy, time, and/or sensory capabilities, females may be able to quickly assess habitat suitability by sensing the reproductive success of previous females [42]. Interestingly, conspecific attraction has been observed across numerous animal taxa [26, 43-45], such as birds, mammals, reptiles, fish, and insects, including other mosquitoes $[19,46]$. For Ae. aegypti, attraction of gravid females to containers with immature conspecifics may seem at first counter-productive [47]. These habitats previously released olfactory cues which have attracted the first gravid mosquito and subsequently the offspring colonised the habitats. Thus it is evident that habitats have potential olfactory cues for more gravid to oviposit with substantial ability to support the larvae developmental needs.

In large laboratory cages, when given choices gravid females of An. gambiae s.l., deposit more eggs in turbid water from natural larval habitats than in clear water [28]. On the other hand, previous studies have shown that habitat water with debris has more larvae and more emerging adults. A plausible reason is that debris is potential food source for the larvae of An. gambiae s.l. [48]. In other studies, the number of eggs laid by the female An. gambiae s.l. during the peak oviposition time has been demonstrated to be affected by the suitability of the habitat resource types [16, 27, 49]. Both laboratory-reared and wild-caught mosquitoes of An. gambiae s.l. have been shown to significantly prefer anopheline habitat water to the culicine habitat water [21]. In two studies involving An. gambiae s.s., Brandon and others demonstrated that, the larval rearing water of the different mosquito strains produced a signal that yielded a positive oviposition response from An. gambiae s.s. gravid females of the same region (strain) [14].This not only implies 
the presence of conspecific attractant but also could be a model for how speciation could arise within related taxa of mosquitoes [14].

Aedes atropalpus is a rock-pool breeder that utilizes the same temporary sites repeatedly in nature. In laboratory experiments, this species preferentially oviposited significantly more eggs in water that had previously held conspecific larvae than in distilled water indicating that the attractive substance was probably a pheromone [50]. The apparent stability and low volatility of the active substance would be advantageous in this habitat; the substance can remain active over long periods and can be reconstituted after the drying and subsequent reflooding of the rock pools. The larvaeproduced activity remained both when the larvae were first purged with kaolin and when the water containing larvae was microfiltered. The active substance resulted in greater egg deposition only when the females came in contact with the solution. Thus it was a contact stimulant rather than an attractant [6].

Conspecific reflects a trade-off between the risk of choosing an unsuitable habitat and the cost of intraspecific competition [5, 30, 32]. For example, larval density can affect site selectivity. Rearing water of higher larval density (900 larvae per liter) was repellent to ovipositing An. atropalpus females reared under axenic conditions [51]. In a previous study, An. gambiae s.s. laid significantly more eggs in containers with low larval density than in containers with higher densities [13]. Probably, this is because those high larval densities negatively influenced several components of anopheline mosquito fitness, including larval survivorship [52], development rate [53], adult lifespan [53], adult size $[31,54]$, and female fecundity [54-56]. From this standpoint, it would seem advantageous for ovipositing females to view conspecifics as competitors to their own progeny [47].

Such threshold of larval density has been demonstrated with Ae. aegypti as well. Laboratory assays have demonstrated a dose-specific oviposition response that increased with conspecific densities up to 1 larva/mL and decreased thereafter [35-37]. An. gambiae s.s. laid significantly more eggs in containers with five larvae than in containers with higher densities (more than 50) [13]. It has been suggested that, at least with Ae. aegypti, a small portion of female population may act as "founders" [57], choosing noncolonized sites based on environmental indicators of quality, whereas the majority of females respond predominantly to conspecific cues [47]. This could be true with An. gambiae s.l. despite the fact that both females have been reported to be using multiple breeding sites for oviposition $[58,59]$. This seemed to occur within a distance of few meters and mainly due to increasing the chance of reducing the risk of progeny failing to develop into adult stage [60].

2.3. Vegetation Volatiles. Middle-range volatiles from plants may function as chemical cues for the female's oviposition response in Anopheles mosquito species. In general, vegetation as visual cues evidently influenced oviposition on soil or water substrates. For example, while Anopheles funestus breeds mainly in marshes and swamps that contain tall grasses, Anopheles hermsi increased with increase in the density of aquatic macrophytes (Myriophylluy maquaticum) up to 1,000 stems per $\mathrm{m}^{2}[24,61]$. Some anopheline species generally prefer to lay eggs in habitats associated with vegetation. Given a choice, Anopheles minimus s.l. prefer to oviposit their eggs where plants are present compared to sites with bare soil. Small-leaved plants were significantly more attractive to ovipositing female of this species compared to habitats with grasses [62].

Anopheles gambiae Giles s.l. has been thought to avoid stagnant water populated with vegetation. This is likely not accurate as the species has been found to deposit eggs in rice fields at all stages of vegetative maturity [63]. Fillinger et al. [64] have strongly challenged the idea that An. gambiae avoids habitats with emergent vegetation like grasses. Minakawa et al. [11] provided evidence that An. gambiae is commonly found in association with grasses, but it was not clear whether presence of larvae in such habitats results from hatched eggs laid on or around wet grasses, or whether larvae were carried there by flowing water. This question has been addressed in laboratory oviposition choice experiments by Huang et al. [65]. They found that $A n$. gambiae s.l. females preferred to lay their eggs on bare wet soil rather than on soil populated with grasses. However, in nochoice experiments, when typical puddles over bare soil are unavailable, An. gambiae s.l. has the capacity to oviposit into grassy aquatic habitats and short grasses were more preferred than medium and tall ones $[48,66]$.

However, some plant species may act as specific attractants more than others. For example, a strong positive association has been found between An. Albimanus Wiedemann larval abundance and specific vegetation forms of water containing Brachiaria mutica, Cynodon dactylon, Jouveastraminea, Fimbristylis spadicea, and Ceratophyllum demersum $[38,67,68]$. This suggested that females of this species may be using cues from these plants to select suitable places to lay their eggs. This has been addressed by an experiment conducted in a wind tunnel and indicated that gravid female of An. albimanus response is mediated by chemical cues from these plants. Gas chromatography and mass spectrometry analysis of the organic extracts from these plants showed a mixture of terpenoid and alcohol compounds, among them: guaiacol, phenol, isoeugenol, longifolene, caryophyllene, phenyl ethyl alcohol, and p-cresol [67].

2.4. Moisture Content. Hydration is one of the critical oviposition site selection qualities for An. gambiae s.l. [27]. In a previous study, a strong positive correlation was found between moisture content and the degree of egg laying, which peaked at saturation with standing water [27]. It has been indicated that these species prefer flooded soil over dry or moist soil as oviposition substrate under the insectary environment. However, when flooded oviposition substrates were removed, females laid all eggs on moist soil substrates [69]. Besides, anopheline eggs remain viable only on wet substrates [24] and gravid females often choose a moist surface to oviposit their eggs in the laboratory and in the field $[16,65,70]$. In general, An. gambiae females are very sensitive 
to small changes in moisture while choosing an oviposition site [27]. Probably, this is because these eggs cannot tolerate prolonged desiccation, an observation not applicable to some mosquitoes, for example, Aedes and Ochlerotatus [24]. Survivorship of An. gambiae s.l. eggs in drying soils held in a laboratory was found to be inversely related to time after deposition; that is, very few eggs in drying soils hatched after 12-15 days upon reflooding [71]. It has been suggested that the egg stage of An. gambiae s.l. might contribute to the shortterm survival of this vector during dry periods in natural conditions [71]. This has further been confirmed in laboratory experiment in which high temperature was found to cause egg mortality [16]. This study concluded that moist mud around puddles constitutes suitable habitat for An. gambiae s.l. eggs; however, eggs on the surface of dry soil under direct sunlight are unlikely to survive for more than a few hours.

2.5. Predator's Kairomones. There are growing lines of evidence that a number of mosquito species detect some predators via chemical cues, causing them to avoid these predators when choosing an oviposition site [13, 19, 30, 41, 72-81]. In general, chemical cues play an important role in predator prey interactions in aquatic environments [82-85]. Predatorreleased kairomones may induce morphological changes in prey [80, 81], foraging changes by prey [86], and behavioral responses of gravid prey females via oviposition habitat selection [87]. Several studies have shown that mosquitoes chemically detect and avoid backswimmer species when ovipositing An. gambiae s.l. species [30,74]. Munga et al. [13] demonstrated that cues from backswimmers and tadpoles influenced selection of oviposition site by gravid An. gambiae s.l. in cages. These results suggested that gravid mosquitoes avoid habitats containing competitors and predators to reduce the risk of mortality of offspring and this behavior is probably one of the mechanisms causing the heterogeneous distribution of An. gambiae s.l. larvae [88].

However, little is known about how malaria vector females detect predator-released kairomones in breeding sites, and no such kairomones have been chemically identified. In general, mosquitoes may detect chemicals from the air when the chemical possesses sufficient volatility or, in the case of low volatility chemicals, by a gustatory mechanism involving direct contact with the water [89]. It has been demonstrated that ovipositing Culiseta longiareolata female in study site here was deterred from continuing to the central pool, without any direct contact, when predator-released volatile compound(s) emanated from the surrounding channel $[80,81]$. Notonecta maculata has already been shown to influence oviposition by three mosquitoes species including An. gambiae s.l. [13], and the predator-released kairomone(s) may have the same effects in all three mosquito species. The chemicals which may be common to all backswimmers species [77], but not to other predator groups [90], elicit the response in some mosquitoes. Future studies should focus on determining the specific volatile compound(s) released by predators that reduce malaria vector oviposition, particularly An. gambiae s.l., which may then be used in control efforts [80].
2.6. Microbial Volatiles. Microbial populations in breeding sites produce volatiles that serve as semiochemicals for gravid An. gambiae. These signals, in conjunction with other (nonolfactory) chemical and physical cues, may be used by the female to assess the suitability of potential larval habitats in order to maximize the fitness of her offspring. Microbes and their metabolites act as ovipositional attractants and/or stimulants for various species of culicine mosquitoes [22, 23, 91-93]. Microbial metabolites emanating from larval habitats might also positively influence ovipositional site selection by anopheline mosquitoes. Indirect lines of evidence have shown that water microbial condition significantly affected oviposition as a substrate preference of anopheline mosquitoes. Knols et al. [17] reported that An. gambiae Giles laid more eggs on nonautoclaved soil or water taken from natural larval habitats than on similar but autoclaved materials, suggesting that killing the microbes by autoclaving eliminated the source of ovipositional attractants. In a laboratory experiment, lake water drawn from Lake Victoria attracted more eggs by An. gambiae than did any water or infusion type, including water from puddle habitats supporting larvae that are thought to be ideal larval habitat. The author speculated that algal volatiles [94, 95] might play some role in ovipositional stimulation on this type of water [49]. Blackwell and Johnson [96] observed significant electroantennogram (EAG) responses of An. gambiae towards volatile components of water samples from Tanzanian breeding sites. The origin of stimulants in mosquito breeding sites and their mode of action towards gravid females are not fully understood, though it has been suggestively linked to microbial activity $[9,15,35,36,97]$.

Previous studies have shown that microbial volatiles function as oviposition attractants/stimulants to different mosquito species. Bacteria in larval habitats may serve as a direct source of food for the larvae or as modifiers of organic matter in breeding waters, which may give rise to constituents ingested by larvae as well as volatile organic compounds of the breeding site waters $[25,96,98-100]$. Certain bacterial volatiles have been shown to attract $C x$. fatigans Coquillet [97], Ae. aegypti L. [92], and Cx. quinquefasciatus Say [18, 93]. In certain cases, bacterial metabolites [97] were thought to be precursors in the synthesis of the volatile attractants. A lower oviposition response was reported after reduction of the number of bacteria either by sterilization, filtering, or addition of antibiotics to the test water or substrate [21, 35, 36, 91]. Indeed, some studies have reported a direct oviposition response toward bacterial cultures or filtrates [16, 23, 92, 93, 97, 101-103]. The majority of these studies have been performed on Culex or Aedes mosquitoes. For anopheline mosquitoes, Sumba et al. [21] observed an indirect effect of bacteria on oviposition response of Anopheles gambiae Giles by comparing soil and water from natural habitats with the same substrate that had been sterilized. The mosquitoes laid significantly more eggs on the nonsterile substrates [21]. Material from larval habitats of Anopheles albimanus Wiedemann and Anopheles vestitipennis Dyar and Knab (consisting of macrophytes, cyanobacteria, diatoms, and bacteria), when extracted by freeze-drying and presented to gravid females at low concentrations, increased oviposition by females of both 
species [100]. Direct evidence has found that emissions from a bacterial flora isolated from a larval habitat of An. gambiae received significantly fewer eggs than controls, indicating that these emissions under the unnatural conditions were repellent rather than attractive to the gravid females [16, $65,104]$. This bacterial flora included mixtures of bacterial colonies of Pseudomonas strains (78\%), Stenotrophomonas, Enterobacter, Pantoea, Klebsiella, Acinetobacter, Aeromonas, and Bacillus or a lawn of colonies of a field isolate of $S$. maltophilia. Oviposition was neither reduced nor enhanced when field isolates of Pseudomonas putida or Pseudomonas alcaligenes colonies were presented in the habitat. These results suggest that gravid An. gambiae females are sensitive to bacteria-derived odors emanating, as has been suggested for host-seeking females [15], from cultured bacteria from natural larval habitats and that some bacterial odors may be repellent [16]. Recently, 13 putative oviposition attractants for An. gambiae mosquitoes were identified from six bacteria, previously isolated from Anopheles gambiae s.l. (Diptera: Culicidae) midguts or oviposition sites, subjected to principal component analysis (PCA) based on the relative amounts of volatiles emitted and among these putative, the 3-methyl-1butanol has been found to be a strong candidate [105]. Further research is needed to confirm these observations. If any of the suggested compounds is confirmed as oviposition attractants, they may be used in traps to monitor or in combination with larvicides to control An. gambiae populations.

Bond et al. [106] provided direct evidence for attraction of gravid Anopheles pseudopunctipennis Theobald to substrates containing filamentous algae. Torres-Estrada et al. [68] investigated the attraction of An. pseudopunctipennis gravid females to oviposition substrates containing Spirogyra majuscula algae under laboratory conditions. This experiment has been done based on the well-documented association of filamentous algae with larval abundance [26]. The authors found that gravid females deposited significantly more eggs in cups containing natural algae in water from breeding sites than in cups containing artificial (nylon rope) life-like algae in water from the corresponding natural breeding site or in cups containing natural algae in distilled water. Results from bioassays carried out in the same study with Spirogyra majuscula organic extracts indicated that these extracts at concentrations of $0.1 \%, 0.01 \%$, and $0.001 \%$ attracted more oviposition, but concentrations of $1 \%, 10 \%$, and $100 \%$ were repellent. Gas chromatography and mass spectrometry analysis of algal organic extracts revealed a mixture of ethyl acetate and hydrocarbons compounds. These results suggested that the attraction of gravid An. pseudopunctipennis to natural breeding sites containing filamentous algae is probably mediated by organic volatiles released by the algae [26].

\section{Conclusion}

Chemical volatiles influence oviposition site selection as attractants or stimulants. Control tools could be therefore designed to capitalize on the attractant or stimulant properties of semiochemicals influencing malaria vectors oviposition responses in the field. The isolation of determinants for oviposition behaviors in anopheline mosquitoes still remained elusive. Efforts for isolating anopheline oviposition pheromones level have been unsuccessful, probably due to small quantity produced by the immature stages making the study of their structure and function more difficult. This review suggests early investigations which indicates the potential of plant, algae, or bacteria-derived oviposition attractants and stimulants, which could be used to lure females mosquitoes to lethal ovitraps to increase their exposure to insecticide-impregnated substrates $[68,105]$.

\section{Conflict of Interests}

The authors declare that they have no conflict of interests.

\section{Authors' Contribution}

Yousif E. Himeidan identified the idea and drafted and wrote up the paper, and Eliningaya J. Kweka, Emmanuel A. Temu, El Amin El Rayah, and Stephen Munga drafted and reviewed the paper. All authors read and approved the final paper.

\section{References}

[1] D. A. Joy, X. Feng, J. Mu et al., "Early origin and recent expansion of Plasmodium falciparum," Science, vol. 300, no. 5617, pp. 318-321, 2003.

[2] World Health Organization, World Malaria Report 2010, World Health Organization, Geneva, Switzerland, http://www. who.int/malaria/world_malaria_report_2010/malaria2010_summary_keypoints_en.pdf.

[3] S. W. Wachira, M. Ndung'u, P. G. N. Njagi, and A. Hassanali, "Comparative responses of ovipositing Anopheles gambiae and Culex quinquefasciatus females to the presence of Culex egg rafts and larvae," Medical and Veterinary Entomology, vol. 24, no. 4, pp. 369-374, 2010.

[4] J. G. Millar, J. D. Chaney, J. W. Beehler, and M. S. Mulla, "Interaction of the Culex quinquefasciatus egg raft pheromone with a natural chemical associated with oviposition sites," Journal of the American Mosquito Control Association, vol. 10, no. 3, pp. 374-379, 1994.

[5] M. Spencer, L. Blaustein, and J. E. Cohen, "Oviposition habitat selection by mosquitoes (Culiseta longiareolata) and consequences for population size," Ecology, vol. 83, no. 3, pp. 669-679, 2002.

[6] M. D. Bentley and J. F. Day, "Chemical ecology and behavioral aspects of mosquito oviposition," Annual Review of Entomology, vol. 34, pp. 401-421, 1989.

[7] E. E. Davis and F. T. Takahashi, "Humoral alteration of chemoreceptor sensitivity in the mosquito," in Proceedings of the International Symposium on Olfaction and Taste, pp. 39-42, IRL Dipterology, London, UK, 1980.

[8] H. Pates and C. Curtis, "Mosquito behavior and vector control," Annual Review of Entomology, vol. 50, pp. 53-70, 2005.

[9] J. E. Gimmg, M. Ombok, L. Kamau, and W. A. Hawley, "Characteristics of larval anopheline (Diptera: Culicidae) habitats in western Kenya," Journal of Medical Entomology, vol. 38, no. 2, pp. 282-288, 2001.

[10] N. Minakawa, C. M. Mutero, J. I. Githure, J. C. Beier, and G. Yan, "Spatial distribution and habitat characterization of anopheline 
mosquito larvae in western Kenya," American Journal of Tropical Medicine and Hygiene, vol. 61, no. 6, pp. 1010-1016, 1999.

[11] N. Minakawa, G. Sonye, M. Mogi, and G. Yan, "Habitat characteristics of Anopheles gambiae s.s. larvae in a Kenyan highland," Medical and Veterinary Entomology, vol. 18, no. 3, pp. 301-305, 2004.

[12] J. W. Beehler, J. P. Webb, and M. S. Mulla, "Spatial and circadian oviposition patterns in an urban population of Culex quinquefasciatus," Journal of the American Mosquito Control Association, vol. 9, no. 4, pp. 385-388, 1993.

[13] S. Munga, N. Minakawa, G. Zhou, O.-O. J. Barrack, A. K. Githeko, and G. Yan, "Effects of larval competitors and predators on oviposition site selection of Anopheles gambiae sensu stricto," Journal of Medical Entomology, vol. 43, no. 2, pp. 221224, 2006.

[14] C. Brandon Ogbunugafor and L. Sumba, "Behavioral evidence for the existence of a region-specific oviposition cue in Anopheles gambiae s.s," Journal of Vector Ecology, vol. 33, no. 2, pp. 321$324,2008$.

[15] W. Takken and B. G. J. Knols, "Odor-mediated behavior of Afrotropical malaria mosquitoes," Annual Review of Entomology, vol. 44, pp. 131-157, 1999.

[16] J. Huang, E. D. Walker, P. E. Otienoburu, F. Amimo, J. Vulule, and J. R. Miller, "Laboratory tests of oviposition by the African malaria mosquito, Anopheles gambiae, on dark soil as influenced by presence or absence of vegetation," Malaria Journal, vol. 5 , article 88, 2006.

[17] B. G. J. Knols, L. A. Sumba, T. O. Guda, A. L. Deng, A. Hassanali, and J. C. Beier, "Mediation of oviposition site selection in the African malaria mosquito Anopheles gambiae (Diptera: Culicidae) by semiochemicals of microbial origin," International Journal of Tropical Insect Science, vol. 24, no. 3, pp. 260-265, 2004.

[18] J. G. Millar, J. D. Chaney, and M. S. Mulla, "Identification of oviposition attractants for Culex quinquefasciatus from fermented Bermuda grass infusions," Journal of the American Mosquito Control Association, vol. 8, no. 1, pp. 11-17, 1992.

[19] A. Mokany and R. Shine, "Competition between tadpoles and mosquito larvae," Oecologia, vol. 135, no. 4, pp. 615-620, 2003.

[20] G. Stay, L. Blaustein, and J. Margalith, "Experimental evidence for predation risk sensitive oviposition by a mosquito, Culiseta longiareolata," Ecological Entomology, vol. 24, no. 2, pp. 202-207, 1999.

[21] L. A. Sumba, K. Okoth, A. L. Deng et al., "Daily oviposition patterns of the African malaria mosquito Anopheles gambiae Giles (Diptera: Culicidae) on different types of aqueous substrates," Journal of Circadian Rhythms, vol. 2, article 6, 2004.

[22] J. D. Trexler, C. S. Apperson, C. Gemeno, M. J. Perich, D. Carlson, and C. Schal, "Field and laboratory evaluations of potential oviposition attractants for Aedes albopictus (Diptera: Culicidae)," Journal of the American Mosquito Control Association, vol. 19, no. 3, pp. 228-234, 2003.

[23] J. D. Trexler, C. S. Apperson, L. Zurek et al., "Role of bacteria in mediating the oviposition responses of Aedes albopictus (Diptera: Culicidae)," Journal of Medical Entomology, vol. 40, no. 6, pp. 841-848, 2003.

[24] A. N. Clements, The Biology of Mosquitoes, CABI, London, UK, 1999.

[25] E. Rejmankova, H. M. Savage, M. H. Rodriguez, D. R. Roberts, and M. Rejmanek, "Aquatic vegetation as a basis for classification of Anopheles albimanus Weideman (Diptera: Culicidae) larval habitats," Environmental Entomology, vol. 21, no. 3, pp. 598-603, 1992.

[26] H. M. Savage, E. Rejmankova, J. I. Arredondo-Jimenez, D. R. Roberts, and M. H. Rodr'iguez, "Limnological and botanical characterization of larval habitats for two primary malarial vectors, Anopheles albimanus and Anopheles pseudopunctipennis, in coastal areas of Chiapas State, Mexico," Journal of the American Mosquito Control Association, vol. 6, no. 4, pp. 612620, 1990.

[27] J. Huang, E. D. Walker, P. Y. Giroux, J. Vulule, and J. R. Miller, "Ovipositional site selection by Anopheles gambiae: influences of substrate moisture and texture," Medical and Veterinary Entomology, vol. 19, no. 4, pp. 442-450, 2005.

[28] A. W. R. McCrae, "Oviposition by African malaria vector mosquitoes. II. Effects of site tone, water type and conspecific immatures on target selection by freshwater Anopheles gambiae Giles, sensu lato," Annals of Tropical Medicine and Parasitology, vol. 78, no. 3, pp. 307-318, 1984.

[29] L. A. Sumba, C. B. Ogbunugafor, A. L. Deng, and A. Hassanali, "Regulation of oviposition in Anopheles gambiae s.s.: role of inter- and intra-specific signals," Journal of Chemical Ecology, vol. 34, no. 11, pp. 1430-1436, 2008.

[30] L. Blaustein, M. Kiflawi, A. Eitam, M. Mangel, and J. E. Cohen, "Oviposition habitat selection in response to risk of predation in temporary pools: mode of detection and consistency across experimental venue," Oecologia, vol. 138, no. 2, pp. 300-305, 2004.

[31] J. E. Gimnig, M. Ombok, S. Otieno, M. G. Kaufman, J. M. Vulule, and E. D. Walker, "Density-dependent development of Anopheles gambiae (Diptera: Culicidae) larvae in artificial habitats," Journal of Medical Entomology, vol. 39, no. 1, pp. 162$172,2002$.

[32] M. Kiflawi, L. Blaustein, and M. Mangel, "Oviposition habitat selection by the mosquito Culiseta longiareolata in response to risk of predation and conspecific larval density," Ecological Entomology, vol. 28, no. 2, pp. 168-173, 2003.

[33] C. J. M. Koenraadt and W. Takken, "Cannibalism and predation among larvae of the Anopheles gambiae complex," Medical and Veterinary Entomology, vol. 17, no. 1, pp. 61-66, 2003.

[34] P. Reiter, M. A. Amador, and N. Colon, "Enhancement of the CDC ovitrap with hay infusions for daily monitoring of Aedes aegypti populations," Journal of the American Mosquito Control Association, vol. 7, no. 1, pp. 52-55, 1991.

[35] G. L. Benzon and C. S. Apperson, "Reexamination of chemically mediated oviposition behavior in Aedes aegypti (L.) (Diptera: Culicidae)," Journal of Medical Entomology, vol. 25, no. 3, pp. 158-164, 1988.

[36] G. L. Benzon, C. S. Apperson, and W. Clay, "Factors affecting oviposition site preference by Toxorhynchites splendens in the laboratory," Journal of the American Mosquito Control Association, vol. 4, no. 1, pp. 20-22, 1988.

[37] N. Zahiri and M. E. Rau, "Oviposition attraction and repellency of Aedes aegypti (Diptera: Culicidae) to waters from conspecific larvae subjected to crowding, confinement, starvation, or infection," Journal of Medical Entomology, vol. 35, no. 5, pp. 782-787, 1998.

[38] J. L. Torres-Estrada, M. H. Rodríguez, L. Cruz-López, and J. I. Arredondo-Jimenez, "Selective oviposition by Aedes aegypti (Diptera: Culicidae) in response to Mesocyclops longisetus (Copepoda: Cyclopoidea) under laboratory and field conditions," Journal of Medical Entomology, vol. 38, no. 2, pp. 188-192, 2001. 
[39] P. J. McCall and M. M. Cameron, "Oviposition pheromones in insect vectors," Parasitology Today, vol. 11, no. 9, pp. 352-355, 1995.

[40] S. A. Allan and D. L. Kline, "Larval rearing water and preexisting eggs influence oviposition by Aedes aegypti and Ae. albopictus (Diptera: Culicidae)," Journal of Medical Entomology, vol. 35, no. 6, pp. 943-947, 1998.

[41] L. Blaustein and B. P. Kotler, "Oviposition habitat selection by the mosquito, Culiseta longiareolata: effects of conspecifics, food and green toad tadpoles," Ecological Entomology, vol. 18, no. 2, pp. 104-108, 1993.

[42] B. Doligez, C. Cadet, E. Danchin, and T. Boulinier, "When to use public information for breeding habitat selection? The role of environmental predictability and density dependence," Animal Behaviour, vol. 66, no. 5, pp. 973-988, 2003.

[43] J. A. Stamps, "Conspecific attraction and aggregation in territorial species," American Naturalist, vol. 131, no. 3, pp. 329-347, 1988.

[44] J. Stamps, R. McElreath, and P. Eason, "Alternative models of conspecific attraction in flies and crabs," Behavioral Ecology, vol. 16, no. 6, pp. 974-980, 2005.

[45] J. K. Young and J. A. Shivik, "What carnivore biologists can learn from bugs, birds, and beavers: a review of spatial theories," Canadian Journal of Zoology, vol. 84, no. 12, pp. 1703-1711, 2006.

[46] S. B. Heard, "Imperfect oviposition decisions by the pitcher plant mosquito (Wyeomyia smithii)," Evolutionary Ecology, vol. 8, no. 5, pp. 493-502, 1994.

[47] J. Wong, S. T. Stoddard, H. Astete, A. C. Morrison, and T. W. Scott, "Oviposition site selection by the dengue vector Aedes aegypti and its implications for dengue control," PLoS Neglected Tropical Diseases, vol. 5, no. 4, Article ID e1015, 2011.

[48] E. J. Kweka, G. Zhou, M.-C. Lee et al., "Evaluation of two methods of estimating larval habitat productivity in western Kenya highlands," Parasites and Vectors, vol. 4, no. 1, article 110, 2011.

[49] P. E. Otienoburu, N. Bayoh, J. Gimnig et al., “Anopheles gambiae (Diptera: Culicidae) oviposition as influenced by type of water infused into black and red soils of western Kenya," International Journal of Tropical Insect Science, vol. 27, no. 1, pp. 2-5, 2007.

[50] K. S. P. Kalpage and R. A. Brust, "Oviposition attractant produced by immature Aedes atropa/pus," Environmental Entomology, vol. 2, pp. 729-730, 1973.

[51] A. Maire, "Effect of axenic larvae on the oviposition site selection by Aedes atropalpus," Journal of the American Mosquito Control Association, vol. 1, no. 3, pp. 320-323, 1985.

[52] P. Schneider, W. Takken, and P. J. McCall, "Interspecific competition between sibling species larvae of Anopheles arabiensis and An. gambiae," Medical and Veterinary Entomology, vol. 14, no. 2, pp. 165-170, 2000.

[53] L. P. Lounibos, N. Nishimura, J. Conn, and R. Lourenço-deOliveira, "Life history correlates of adult size in the malaria vector Anopheles darlingi," Memórias do Instituto Oswaldo Cruz, vol. 90, no. 6, pp. 769-774, 1995.

[54] W. Takken, M. J. Klowden, and G. M. Chambers, "Effect of body size on host seeking and blood meal utilization in Anopheles gambiae sensu stricto (Diptera: Culicidae): the disadvantage of being small," Journal of Medical Entomology, vol. 35, no. 5, pp. 639-645, 1998.

[55] B. Ameneshewa and M. W. Service, "The relationship between female body size and survival rate of the malaria vector Anopheles arabiensis in Ethiopia," Medical and Veterinary Entomology, vol. 10, no. 2, pp. 170-172, 1996.
[56] E. O. Lyimo and W. Takken, "Effects of adult body size on fecundity and the pregravid rate of Anopheles gambiae females in Tanzania," Medical \& Veterinary Entomology, vol. 7, no. 4, pp. 328-332, 1993.

[57] R. J. Toonen and J. R. Pawlik, "Foundations of gregariousness," Nature, vol. 370, no. 6490, pp. 511-512, 1994.

[58] B. L. Apostol, W. C. Black IV, P. Reiter, and B. R. Miller, "Use of randomly amplified polymorphic DNA amplified by polymerase chain reaction markers to estimate the number of Aedes aegypti families at oviposition sites in San Juan, Puerto Rico," American Journal of Tropical Medicine and Hygiene, vol. 51, no. 1, pp. 89-97, 1994.

[59] H. Chen, U. Fillinger, and G. Yan, "Oviposition behavior of female Anopheles gambiae in eestern Kenya inferred from microsatellite markers," American Journal of Tropical Medicine and Hygiene, vol. 75, no. 2, pp. 246-250, 2006.

[60] F. M. Mutuku, J. A. Alaii, M. N. Bayoh et al., "Distribution, description, and local knowledge of larval habitats of Anopheles gambiae s.l. in a village in western Kenya," American Journal of Tropical Medicine and Hygiene, vol. 74, no. 1, pp. 44-53, 2006.

[61] B. K. Orr and V. H. Resh, "Experimental test of the influence of aquatic macrophyte cover on the survival of Anopheles larvae," Journal of the American Mosquito Control Association, vol. 5, no. 4, pp. 579-585, 1989.

[62] H. J. Overgaard, "Effect of plant structure on oviposition behavior of Anopheles minimus s.1," Journal of Vector Ecology, vol. 32, no. 2, pp. 193-197, 2007.

[63] R. C. Muirhead-Thomson, "Studies on the breeding places and control of Anopheles gambiae and A. gambiae var. melas in coastal districts of Sierra Leone," Bulletin of Entomological Research, vol. 36, pp. 185-252, 1945.

[64] U. Fillinger, G. Sonye, G. F. Killeen, B. G. J. Knols, and N. Becker, "The practical importance of permanent and semipermanent habitats for controlling aquatic stages of Anopheles gambiae sensu lato mosquitoes: operational observations from a rural town in western Kenya," Tropical Medicine and International Health, vol. 9, no. 12, pp. 1274-1289, 2004.

[65] J. Huang, J. R. Miller, S.-C. Chen, J. M. Vulule, and E. D. Walker, "Anopheles gambiae (Diptera: Culicidae) oviposition in response to agarose media and cultured bacterial volatiles," Journal of Medical Entomology, vol. 43, no. 3, pp. 498-504, 2006.

[66] S. Munga, J. Vulule, and E. J. Kweka, "Response of Anopheles gambiae s.l. (Diptera: Culicidae) to larval habitat age in western Kenya highlands," Parasites \& Vectors, vol. 6, p. 13, 2013.

[67] J. L. Torres-Estrada, R. A. Meza-Alvarez, J. Cibrián-Tovar et al., "Vegetation-derived cues for the selection of oviposition substrates by Anopheles albimanus (Diptera: Culicidae) under laboratory conditions," Journal of the American Mosquito Control Association, vol. 21, pp. 344-349, 2005.

[68] J. L. Torres-Estrada, R. A. Meza-Álvarez, L. Cruz-López, M. H. Rodríguez, and J. I. Arredondo-Jiménez, "Attraction of gravid Anopheles pseudopunctipennis females to oviposition substrates by Spirogyra majuscula (Zygnematales: Zygnmataceae) algae under laboratory conditions," Journal of the American Mosquito Control Association, vol. 23, no. 1, pp. 18-23, 2007.

[69] N. Minakawa, J. I. Githure, J. C. Beier, and G. Yan, "Anopheline mosquito survival strategies during the dry period in western Kenya," Journal of Medical Entomology, vol. 38, no. 3, pp. 388392, 2001.

[70] J. K. Olson and C. L. Meek, "Soil moisture conditions that are most attractive to ovipositing females of Psorophora columbiae in Texas rice lands," Mosquito News, vol. 37, pp. 19-26, 1977. 
[71] J. C. Beier, R. Copeland, C. Oyaro et al., “Anopheles gambiae complex egg-stage survival in dry soil from larval development sites in western Kenya," Journal of the American Mosquito Control Association, vol. 6, no. 1, pp. 105-109, 1990.

[72] K. A. Angelon and J. W. Petranka, "Chemicals of predatory mosquitofish (Gambusia affinis) influence selection of oviposition site by Culex mosquitoes," Journal of Chemical Ecology, vol. 28, no. 4, pp. 797-806, 2002.

[73] L. Blaustein, "Spatial distributions of Anopheles freeborni, Gambusia affinis and Lepomis cyanellus in experimental rice plots," Journal of the American Mosquito Control Association, vol. 5, no. 2, pp. 254-257, 1989.

[74] L. Blaustein, J. Blaustein, and J. Chase, "Chemical detection of the predator Notonecta irrorata by ovipositing Culex mosquitoes," Journal of Vector Ecology, vol. 30, no. 2, pp. 299301, 2005.

[75] L. Blaustein and R. Byard, "Predation by a cyprinodontid fish, Aphanius mento, on Culex pipiens: effects of alternative prey and vegetation," Journal of the American Mosquito Control Association, vol. 9, no. 3, pp. 356-358, 1993.

[76] L. Blaustein and J. M. Chase, "Interactions between mosquito larvae and species that share the same trophic level," Annual Review of Entomology, vol. 52, pp. 489-507, 2007.

[77] A. Eitam, L. Blaustein, and M. Mangel, "Effects of Anisops sardea (Hemiptera: Notonectidae) on oviposition habitat selection by mosquitoes and other dipterans and on community structure in artificial pools," Hydrobiologia, vol. 485, pp. 183189, 2002.

[78] P. J. McCall, "Chemoecology of oviposition in insects of medical and veterinary importance," in Chemoecology of Insect Eggs and Egg Deposition, M. Hilker and T. Meiners, Eds., pp. 265-290, 2002.

[79] J. W. Petranka and K. Fakhoury, "Evidence of a chemically mediated avoidence response of ovipositing insects to blue gills and green frog tadpoles," Copeia, vol. 1, pp. 234-239, 1991.

[80] A. Silberbush and L. Blaustein, "Oviposition habitat selection by a mosquito in response to a predator: are predator-released kairomones air-borne cues?" Journal of Vector Ecology, vol. 33, no. 1, pp. 208-211, 2008.

[81] A. Silberbush, S. Markman, E. Lewinsohn, E. Bar, J. E. Cohen, and L. Blaustein, "Predator-released hydrocarbons repel oviposition by a mosquito," Ecology Letters, vol. 13, no. 9, pp. 11291138, 2010.

[82] S. I. Dodson and T. Hanazato, "Commentary on effects of anthropogenic and natural organic chemicals on development, swimming behavior, and reproduction of Daphnia, a key member of aquatic ecosystems," Environmental Health Perspectives, vol. 103, supplement 4, pp. 7-11, 1995.

[83] S. I. Dodson, T. A. Crowl, B. L. Peckarsky, L. B. Kats, A. P. Covich, and M. Joseph Culp, "Nonvisual communication in freshwater benthods-an overview," Journal of the North American Benthological Society, vol. 13, pp. 268-282, 1994.

[84] J. W. Petranka, L. B. Kats, and A. Sih, "Predator-prey interactions among fish and larval amphibians: use of chemical cues to detect predatory fish," Animal Behaviour, vol. 35, no. 2, pp. 420-425, 1987.

[85] B. D. Wisenden, "Olfactory assessment of predation risk in the aquatic environment," Philosophical Transactions of the Royal Society B, vol. 355, no. 1401, pp. 1205-1208, 2000.

[86] T. M. McCarthy and B. F. Dickey, "Chemically mediated effects of injured prey on behavior of both prey and predators," Behaviour, vol. 139, no. 5, pp. 585-602, 2002.
[87] G. Orizaola and F. Braña, "Do predator chemical cues affect oviposition site selection in newts?" Herpetological Journal, vol. 13, no. 4, pp. 189-193, 2003.

[88] N. Minakawa, S. Munga, F. Atieli et al., "Spatial distribution of anopheline larval habitats in Western Kenyan highlands: effects of land cover types and topography," American Journal of Tropical Medicine and Hygiene, vol. 73, no. 1, pp. 157-165, 2005.

[89] A. N. Clements, The Biology of Mosquitoes, Chapman \& Hall, CABI, London, UK, 1992.

[90] G. Stav, L. Blaustein, and Y. Margalit, "Influence of nymphal Anax imperator (Odonata: Aeshnidae) on oviposition by the mosquito Culiseta longiareolata (Diptera: Culicidae) and community structure in temporary pools," Journal of Vector Ecology, vol. 25, no. 2, pp. 190-202, 2000.

[91] J. W. Beehler, J. G. Millar, and M. S. Mulla, "Protein hydrolysates and associated bacterial contaminants as oviposition attractants for the mosquito Culex quinquefasciatus," Medical and Veterinary Entomology, vol. 8, no. 4, pp. 381-385, 1994.

[92] E. I. Hazard, M. S. Mayer, and K. E. Savage, "Attraction and oviposition stimulation of gravid female mosquitoes by bacteria isolated from hay infusions," Mosquito News, vol. 27, pp. 133-136, 1967.

[93] S. Poonam, K. P. Paily, and K. Balaraman, "Oviposition attractancy of bacterial culture filtrates-response of Culex quinquefasciatus," Memorias do Instituto Oswaldo Cruz, vol. 97, no. 3, pp. 359-362, 2002.

[94] C. Höckelmann, T. Moens, and F. Jüttner, "Odor compounds from cyanobacterial biofilms acting as attractants and repellents for free-living nematodes," Limnology and Oceanography, vol. 49, no. 5, pp. 1809-1819, 2004.

[95] R. Kambourova, V. Bankova, and G. Petkov, "Volatile substances of the green alga Scenedesmus incrassatulus," Zeitschrift für Naturforschung C, vol. 58, no. 3-4, pp. 187-190, 2003.

[96] A. Blackwell and S. N. Johnson, "Electrophysiological investigation of larval water and potential oviposition chemo-attractants for Anopheles gambiae s.s," Annals of Tropical Medicine and Parasitology, vol. 94, no. 4, pp. 389-398, 2000.

[97] T. Ikeshoji, K. Saito, and A. Yano, "Bacterial production of the ovipositional attractants for mosquitoes on fatty acid substrates," Applied Entomology and Zoology, vol. 10, pp. 239-242, 1975.

[98] D. M. A. F. Navarro, P. E. S. de Oliveira, R. P. J. Potting, A. C. Brito, S. J. F. Fital, and A. E. Goulart Sant'Ana, "The potential attractant or repellent effects of different water types on oviposition in Aedes aegypti L. (Dipt., Culicidae)," Journal of Applied Entomology, vol. 127, no. 1, pp. 46-50, 2003.

[99] E. Rejmánková and J. Komárková, "A function of cyanobacterial mats in phosphorus-limited tropical wetlands," Hydrobiologia, vol. 431, no. 2-3, pp. 135-153, 2000.

[100] E. Rejmánková, R. Higashi, J. Grieco, N. Achee, and D. Roberts, "Volatile substances from larval habitats mediate species-specific oviposition in Anopheles mosquitoes," Journal of Medical Entomology, vol. 42, no. 2, pp. 95-103, 2005.

[101] J. Huang, E. D. Walker, J. Vulule, and J. R. Miller, "Daily temperature profiles in and around Western Kenyan larval habitats of Anopheles gambiae as related to egg mortality," Malaria Journal, vol. 5, article 87, 2006.

[102] S. G. Pavlovich and C. L. Rockett, "Color, bacteria, and mosquito eggs as ovipositional attractants for Aedes aegypti and Aedes albopictus (Diptera: Culicidae)," Great Lakes Entomologist, vol. 33, no. 2, pp. 141-153, 2000. 
[103] C. L. Rockett, "Bacteria as oviposition attractants for Culex pipiens (Diptera: Culicidae)," Great Lakes Entomologist, vol. 20, pp. 151-155, 1987.

[104] D. Hasselschwert and C. L. Rockett, "Bacteria as ovipositional attractants for Aedes aegypti (Diptera, Culicidae)," Great Lakes Entomologist, vol. 21, pp. 163-168, 1988.

[105] J. M. Lindh, A. Kännaste, B. G. J. Knols, I. Faye, and A.-K. Borg-Karlson, "Oviposition responses of Anopheles gambiae s.s. (Diptera: Culicidae) and identification of volatiles from bacteria-containing solutions," Journal of Medical Entomology, vol. 45, no. 6, pp. 1039-1049, 2008.

[106] J. G. Bond, J. C. Rojas, J. I. Arredondo-Jiménez, H. QuirozMartínez, J. Valle, and T. Williams, "Population control of the malaria vector Anopheles pseudopunctipennis by habitat manipulation," Proceedings of the Royal Society B, vol. 271, no. 1553, pp. 2161-2169, 2004 

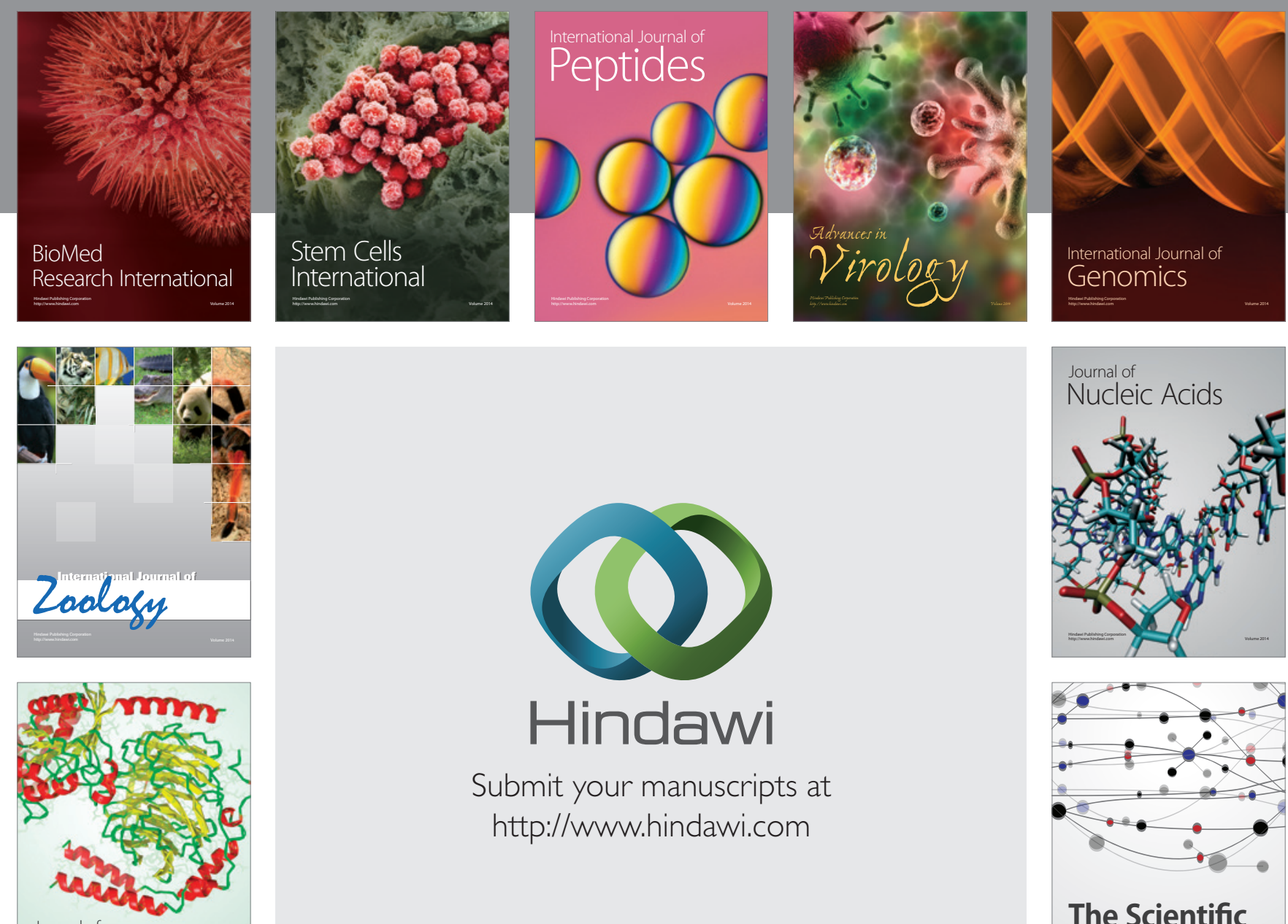

Submit your manuscripts at

http://www.hindawi.com

Journal of
Signal Transduction
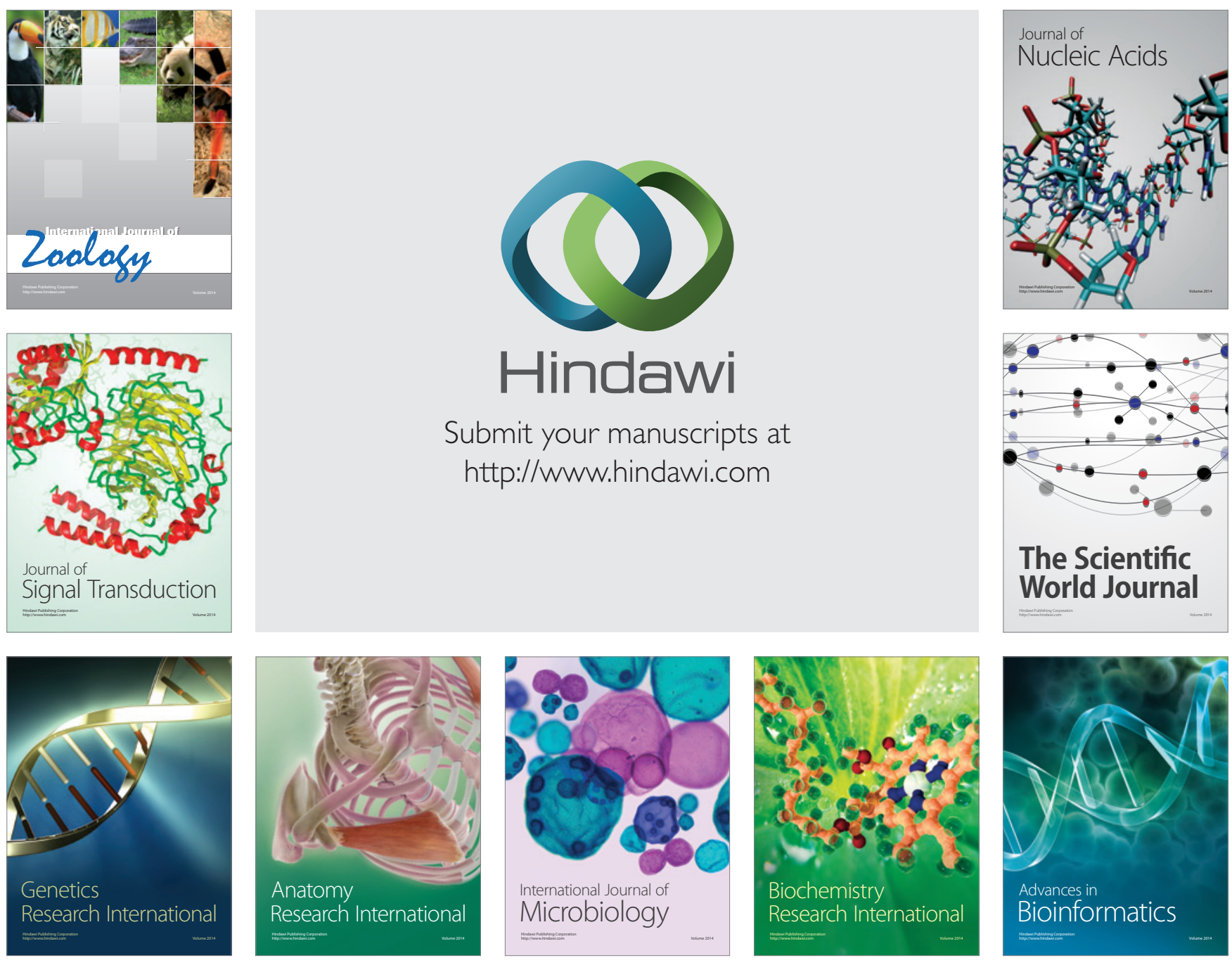

The Scientific World Journal
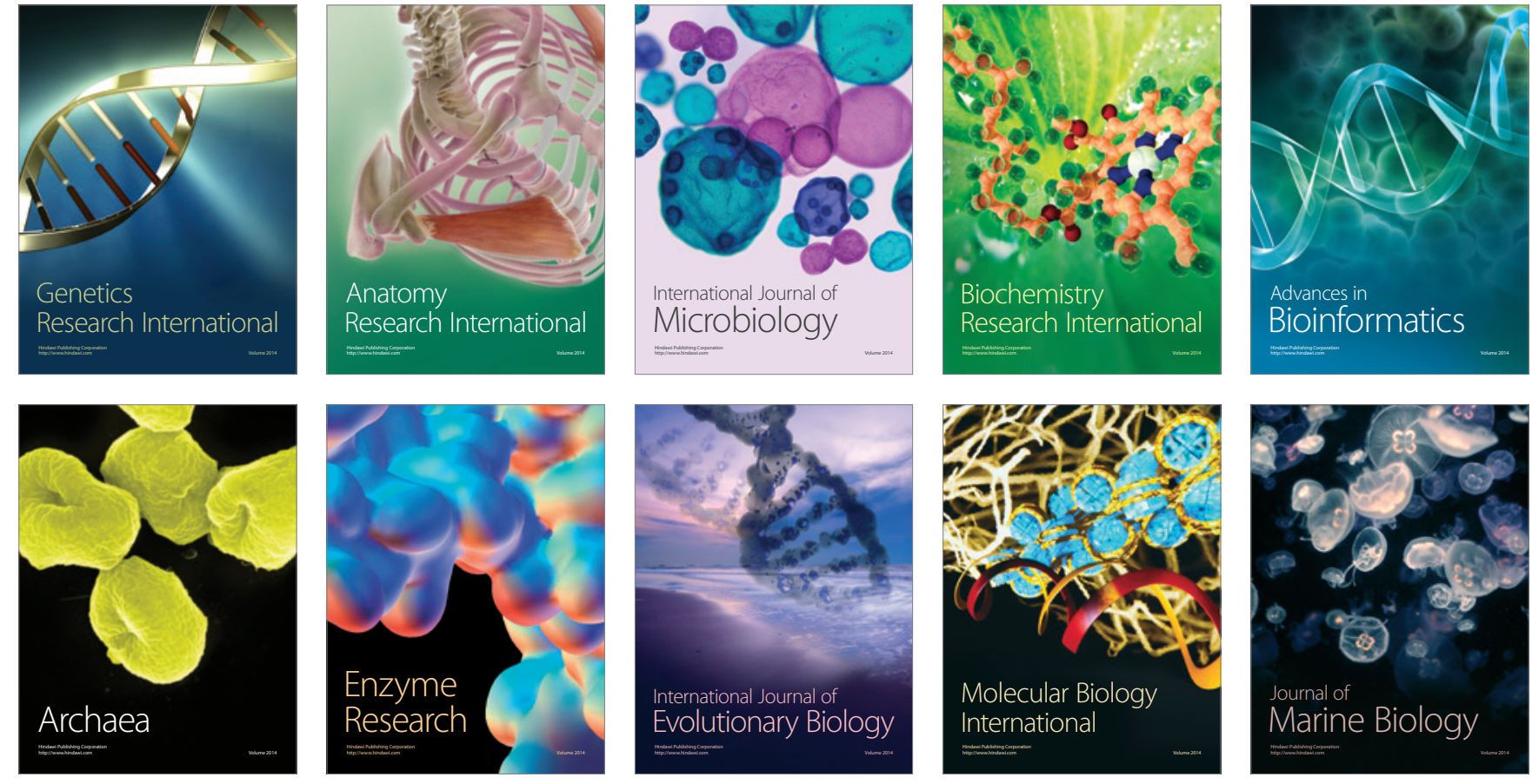